BMJ Open

Diabetes

Research

\& Care

\title{
Predictors of 30-day unplanned hospital readmission among adult patients with diabetes mellitus: a systematic review with meta-analysis
}

\author{
Jade Gek Sang Soh (1) , 1,2 Wai Pong Wong, ${ }^{2}$ Amartya Mukhopadhyay, ${ }^{3,4}$ \\ Swee Chye Quek, ${ }^{5}$ Bee Choo Tai ${ }^{1}$
}

To cite: Soh JGS, Wong WP, Mukhopadhyay A, et al. Predictors of 30-day unplanned hospital readmission among adult patients with diabetes mellitus: a systematic review with meta-analysis. BMJ Open Diab Res Care 2020;8:e001227. doi:10.1136/ bmjdrc-2020-001227

\section{- Additional material is} published online only. To view please visit the journal online (http://dx.doi.org/10.1136/ bmjdrc-2020-001227).

Received 25 January 2020 Revised 18 June 2020 Accepted 22 June 2020
Check for updates

C Author(s) (or their employer(s)) 2020. Re-use permitted under CC BY-NC. No commercial re-use. See rights and permissions. Published by BMJ.

For numbered affiliations see end of article.

Correspondence to Professor Bee Choo Tai; ephtbc@nus.edu.sg

\section{ABSTRACT}

Adult patients with diabetes mellitus (DM) represent one-fifth of all 30-day unplanned hospital readmissions but some may be preventable through continuity of care with better DM self-management. We aim to synthesize evidence concerning the association between 30-day unplanned hospital readmission and patient-related factors, insurance status, treatment and comorbidities in adult patients with DM. We searched full-text English language articles in three electronic databases (MEDLINE, Embase and $\mathrm{CINAHL}$ ) without confining to a particular publication period or geographical area. Prospective and retrospective cohort and case-control studies which identified significant risk factors of 30-day unplanned hospital readmission were included, while interventional studies were excluded. The study participants were aged $\geq 18$ years with either type 1 or $2 \mathrm{DM}$. The random effects model was used to quantify the overall effect of each factor. Twenty-three studies published between 1998 and 2018 met the selection criteria and 18 provided information for the meta-analysis. The data were collected within a period ranging from 1 to 15 years. Although patient-related factors such as age, gender and race were identified, comorbidities such as heart failure $(\mathrm{OR}=1.81$, $95 \% \mathrm{Cl} 1.67$ to 1.96$)$ and renal disease $(\mathrm{OR}=1.69,95 \% \mathrm{Cl}$ 1.34 to 2.12$)$, as well as insulin therapy $(\mathrm{OR}=1.45,95 \% \mathrm{Cl}$ 1.24 to 1.71$)$ and insurance status $(\mathrm{OR}=1.41,95 \% \mathrm{Cl} 1.22$ to 1.63) were stronger predictors of 30-day unplanned hospital readmission. The findings may be used to target DM self-management education at vulnerable groups based on comorbidities, insurance type, and insulin therapy.

\section{INTRODUCTION}

Diabetes is a long-term condition characterized by hyperglycemia when the pancreas is unable to produce enough insulin or when the body is not able to use the insulin effectively to regulate blood sugar level. ${ }^{1}$ The former is known as type 1 diabetes mellitus (T1DM) and the latter as type 2 diabetes mellitus (T2DM). ${ }^{2}$ With advances in diagnosis and treatment, lifespan for patients with diabetes mellitus (DM), which commonly includes both types of diabetes, is projected to be longer. ${ }^{3}$ Increased lifespan and the high prevalence of obesity worldwide have quadrupled the number of adults living with DM from 108 million in 1980 to 422 million in $2014 .^{4}$ Globally, DM accounts for $1.9 \%$ of total disability-adjusted life years ${ }^{5}$ and approximately $30 \%$ of hospitalized adult patients with DM had two or more readmissions within the next calendar year. ${ }^{6}$ Complications from diabetes are a serious threat to healthcare systems and also one of the top 10 causes of public hospital readmissions worldwide. ${ }^{7}$ In 2017, the hospitalization cost of patients with DM in the USA was $\$ 123$ billion. Based on a $20 \%$ readmission rate, it was estimated that $\$ 24.6$ billion would be attributed to 30 -day readmission. ${ }^{8}$ Patients with DM represent one-fifth of the overall 30-day hospital readmissions although some may be preventable through better continuity of care. ${ }^{10}$

Systematic reviews (SR) of DM have mainly focused on the relationship between glycemic control and surgical outcomes ${ }^{11}$ and the economic cost to the health system. ${ }^{13}$ To our knowledge, no SR with meta-analysis (MA) has been conducted to evaluate the effect of patient characteristics on hospital readmission among adult patients with DM. Current literature suggests conflicting results in common risk factors such as gender with some studies showing a significant effect ${ }^{1415}$ while others demonstrating no evidence of relationship. ${ }^{16}$ Patient characteristics such as gender, age, race, and comorbidities may affect the outcomes of self-management. Thus, the US National Standards for Diabetes Self-Management Education and Support Task Force emphasizes their importance ${ }^{17}$ in self-management education (SME), to achieve better control of glycated hemoglobin (HbAlc) levels and reduce macrovascular complications of DM. ${ }^{18}$ 


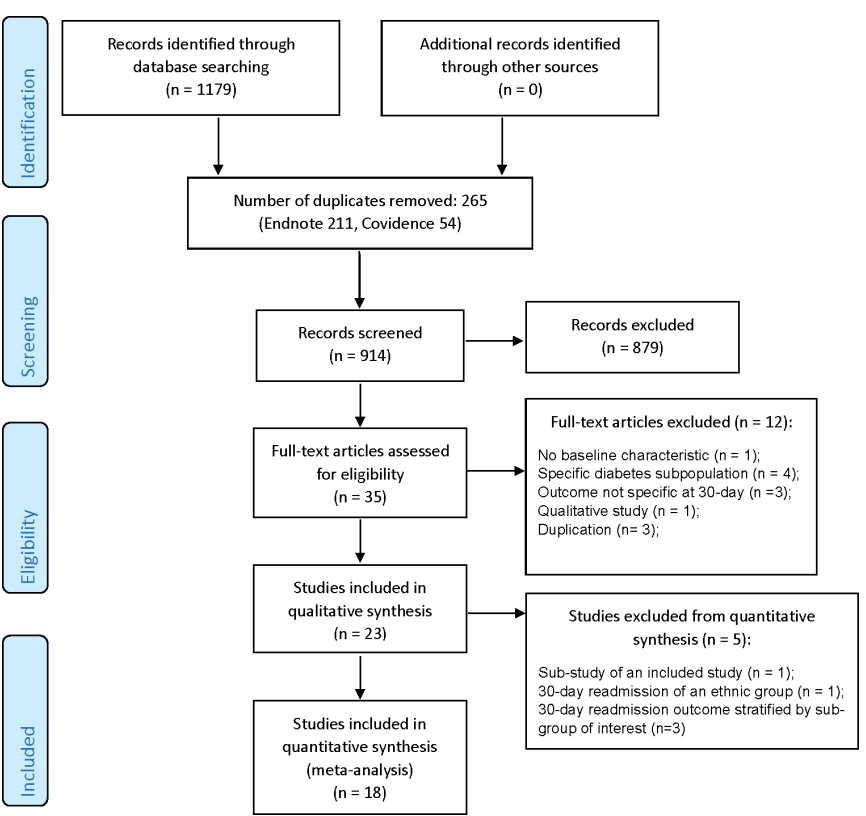

Figure 1 Preferred Reporting Items for Systematic Reviews and Meta-Analyses (PRISMA) flowchart of database search and study selection.

The primary objective of this SR with MA is to synthesize evidence concerning the association between 30-day unplanned hospital readmissions and patient characteristics (namely gender, age and race), affordability of medical insurance (as a proxy measurement of socioeconomic status (SES)), comorbidities, diabetes-related medications and inpatient factors such as length of stay (LOS) of index admission in adult patients with T1DM or T2DM.

\section{METHOD}

The protocol for this review was developed in accordance with the structure of the Preferred Reporting Items for Systematic Review and Meta-Analysis Protocols ${ }^{19}$ and registered with PROSPERO (reference number: CRD42019132375).

\section{Search strategy}

The first reviewer (JGSS) conducted a systematic and comprehensive search of Embase (online supplementary appendix 1), MEDLINE (Ovid SP (online supplementary appendix 2)), and Cumulative Index to Nursing and Allied Health Literature (CINAHL (online supplementary appendix 3)) with the assistance of a universitybased medical librarian experienced in online database searching. The search was restricted to full-text journal articles in the English language as excluding studies in other languages does not lead to any bias. ${ }^{20}$ An SR found no evidence to support previous speculation that positive results tend to be published in English and negative results in non-English language journals. ${ }^{20}$ Social determinants of health such as SES and patient characteristics are associated with health outcomes ${ }^{21}$ but such association may vary over time and locations. Therefore, we did not specify a particular publication period or origin from a specific geographical area. We used Medical Subject Headings (MeSH) terms in MEDLINE (Ovid SP) and 'Emtree' in Embase (as it has similar features to MeSH) to conduct the search. Emtree subject headings like 'diabetes mellitus' were explored with other relevant search terms such as 'readmission' and 'rehospitalization'. A similar search strategy was also applied to identify relevant studies in other medical databases. A complete list of search strategies for all databases is provided in online supplementary materials.

\section{Study design and selection criteria}

We included both cohort and case-control studies reporting the association between patient characteristics and comorbidities with 30-day unplanned hospital readmission. Interventional studies evaluating the effect of an intervention on readmission are excluded. Further exclusions include editorials, commentaries, conference proceedings, case reports, case series, qualitative studies, secondary research and gray literature such as unpublished data and government regulatory documents. The latter represents only a small proportion and rarely impacts on the findings of a review. ${ }^{22}$ The study participants were restricted to adults aged 18 years and above. Both T1DM and T2DM were included while gestational diabetes was excluded from the study. The outcome is 30-day unplanned hospital readmission, which is internationally recognized as a performance indicator of hospital care. ${ }^{23}$

\section{Data management and extraction}

The final search results yielded 1179 records from all the selected databases, which were merged in EndNote library (figure 1). Two hundred and eleven duplicate studies were removed, and the remaining articles were exported to Covidence (Veritas, Health Innovation, Melbourne), ${ }^{24}$ an SR management tool. A further 54 duplicates were identified, leaving 914 studies for screening. We used Covidence to streamline titles, screen abstracts, review full texts, select studies, assess risk bias, record study characteristics, extract and export data to RevMan V.5.3 (Nordic Cochrane Centre, Copenhagen). ${ }^{25}$ The latter was used for data analysis.

\section{Selection process}

The first (JGSS) and the second (WPW) reviewers independently screened the titles and abstracts of the imported articles published between 1998 and 2018 according to the predefined eligibility criteria. They discussed and resolved nine discrepancies during screening for fulltext review. The Newcastle-Ottawa Scale (NOS) was used to evaluate the quality of the papers and assess risk of bias of the selected studies for MA. ${ }^{26}$ The NOS contains eight items in three broad domains: selection of the study groups, comparability of the study groups, and ascertainment of either the exposure or outcome of interest. ${ }^{26}$ The possible scores ranged from 0 to 9 , with a score $\geq 7$ 
generally regarded as low risk of bias. ${ }^{26}$ Consensus was reached at each phase before exporting the data to RevMan V.5.3. In seven studies where the number of cases pertaining to the outcome of interest was not available, the authors were contacted to provide the details.

\section{Type of risk factors}

Three demographic variables were considered as important baseline patient characteristics (namely gender, age and race) while health insurance type was regarded as a key social factor. The most commonly reported comorbid conditions such as heart failure, respiratory disease, depression, renal disease and hypertension were also of interest. LOS of index hospitalization (days) was frequently described and presented as a continuous variable in relation to readmission. Among all types of DM medications, insulin was the most commonly reported.

Age was dichotomized into $<65$ and $\geq 65$ years, a convention and universal cut-off to define old age. ${ }^{27} \mathrm{~A}$ variety of non-White races were included in the selected articles but with low frequencies; we therefore classified race as White versus non-White and excluded unknown race to avoid any misrepresentation of the overall effect. We compared Medicare and/or Medicaid versus private insurance (including Health Maintenance Organization, Preferred Provider Organization, Fee-for-Service, Point of Service Plans and any other commercial insurance). Data accuracy for the pooled analyses was verified and confirmed by both reviewers. All outcomes were presented using the OR and its $95 \%$ CI with the pooled estimate obtained based on T1DM and T2DM combined as presented in most studies.

\section{Assessment of heterogeneity and publication bias}

The study subjects of the selected articles were clinically heterogeneous. For example, some studies evaluated both patients with T1DM and T2DM while others focused solely on patients with T2DM. The duration of the data collection period varied from 1 to 15 years across the selected studies. Thus, a random effects model was used to estimate the overall effect in the pooled analysis. This assumes that the studies represented a random sample from a larger population, with each study having its own underlying effect size and study-specific OR. Publication bias was evaluated by visually assessing the funnel plot when there were at least 10 studies included in the MA. ${ }^{28}$ In addition, the Egger regression test was performed, where a $\mathrm{p}$ value $<0.1$ was specified to indicate publication bias. $^{29}$

\section{RESULTS}

We screened 914 studies and 879 were deemed as irrelevant to the review questions and hence excluded from the full-text review (figure 1). We further excluded 12 studies which did not include the outcome of interest, were of inappropriate designs or involved duplicates. Thus, 23 articles were included for SR (qualitative synthesis) and 18 studies were included in the MA (quantitative synthesis). The respective reasons for exclusion are listed in figure 1 .

\section{Characteristics of studies}

The characteristics of the included studies are summarized in table 1 . The publication year ranged from 1998 to 2018 and nearly $90 \%$ of the studies were published in the last 10 years. Except for two case-control studies, ${ }^{14} 30$ the rest were retrospective cohort studies. ${ }^{910151631-47}$ The mean NOS score of the 21 cohort studies as assessed by the two independent reviewers was 8.3 and 7.9, respectively, suggesting that the articles were of good quality. ${ }^{48}$ Both assessors gave a mean score of 8.0 for the casecontrol studies. Twenty-one studies were conducted in the USA, with one each from the UK and Australia.

\section{Characteristics of patients}

The age of all patients was at least 18 years. In particular, there were six studies ${ }^{1631-35}$ which included patients above 85 years of age. The studies identified patients from either electronic health records $(n=711109)$ or administrative healthcare claims databases $(n=37681$ 177). The International Classification of Diseases, Ninth Revision (ICD-9) 250 code series was commonly used to define DM. However, an Australian study ${ }^{32}$ used the ICD-10, with modification. Two studies ${ }^{31} 44$ did not explicitly state how diagnosis of diabetes was ascertained, although data sources were mentioned. Most studies included both T1DM and T2DM ( $\mathrm{n}=36825$ 049), except seven studies ${ }^{1435} 364045-47$ which focused solely on T2DM ( $n=1567237$ ). Nearly half of the studies from the USA $^{910} 141536-4043$ comprised commercially insured, Medicare, and Medicaid patients; six studies ${ }^{31} 33-354145$ exclusively included Medicare beneficiaries and one study ${ }^{16}$ involved privately insured patients. The Australian study $^{32}$ included only subsidized veterans, war widows or widowers and a study in $\mathrm{UK}^{44}$ encompassed patients under the National Health Service with information on the Index of Multiple Deprivation. ${ }^{49}$

\section{SR of 23 studies}

The prevalence of 30-day hospital readmission in 13 of the selected studies ranged widely from $10 \%$ to $24.6 \%{ }^{32} 36$ with 11 studies $^{910} 14-16303435394147$ reporting a prevalence of at least $15 \%$. Risk factors reported in these studies included key demographics, associated comorbidities and DM-related treatments. One study ${ }^{40}$ that combined different types of comorbidities was excluded in the MA because pooled analysis of separate comorbidities for 30-day hospital readmission was not possible. Nevertheless, it was noted that most of the 30-day hospital readmissions included a combination of comorbidities such as hypertension and renal disease. Three studies provided only subgroup estimates of 30-day readmission by: high versus moderate versus lowdensity neighborhood ${ }^{33}$ hyperglycemia versus hypoglycemia, ${ }^{41}$ and optimal control of low-density lipoprotein 
Table 1 Characteristics of studies identifying significant risk factor for patients with diabetes

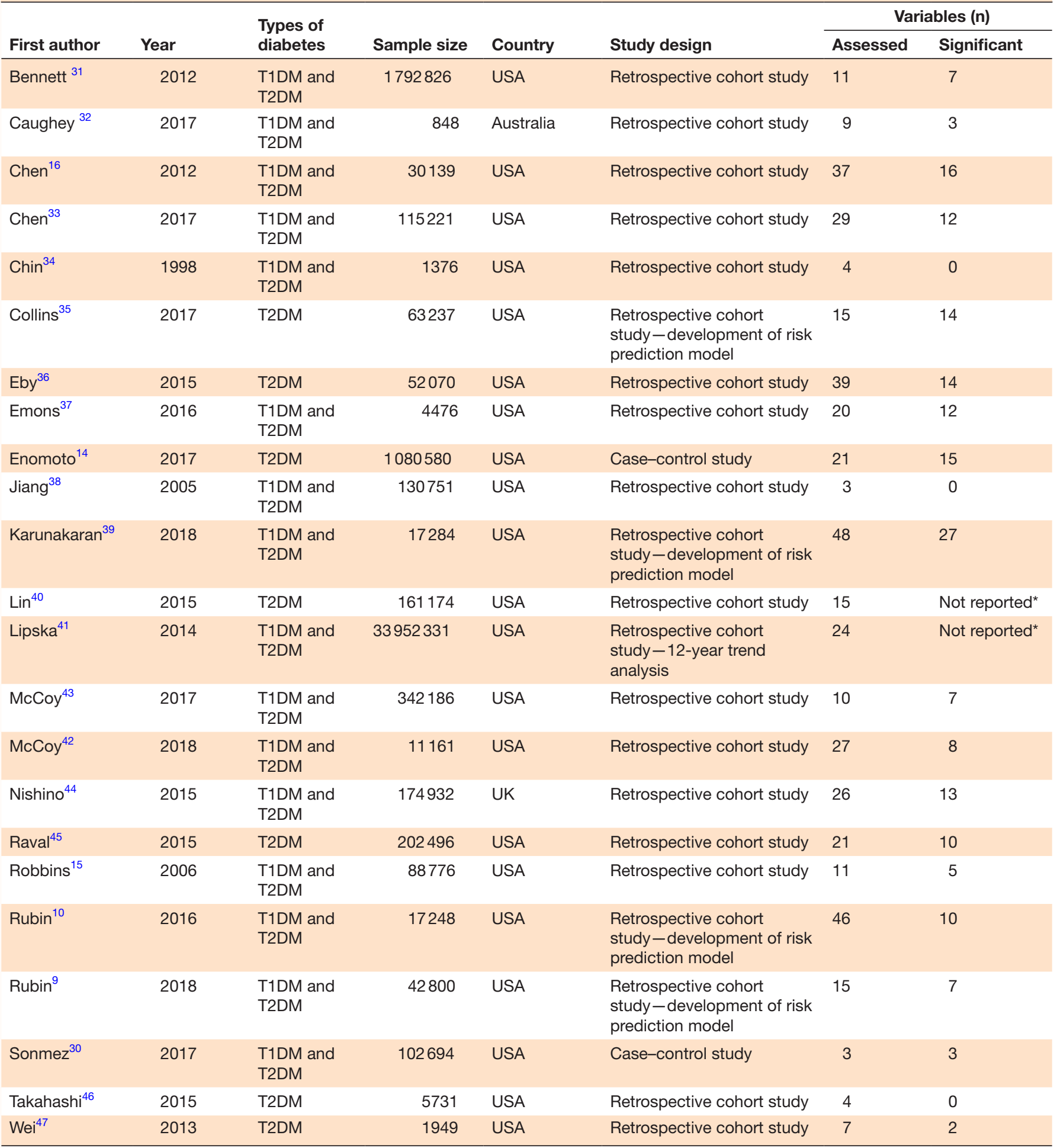

The variables are significant in multivariable analysis.

${ }^{*}$ These studies were only included in the systematic review, as statistical significance was not formally evaluated and they did not provide sufficient information to be included in the meta-analysis.

T1DM, type 1 diabetes mellitus; T2DM, type 2 diabetes mellitus.

cholesterol, blood pressure and HbA1c versus nonoptimal control. ${ }^{46}$ There was no difference in 30-day hospital readmission between the above-mentioned subgroups in two of the studies ${ }^{41} 46$ while Chen et $a l^{33}$ found an increased risk of 30-day hospital readmission among the African-Americans in moderate or highdensity neighborhoods as compared with White race. We excluded these three studies ${ }^{33} 4146$ from subsequent MA as they did not provide relevant risk estimates for the entire study population. We further excluded 


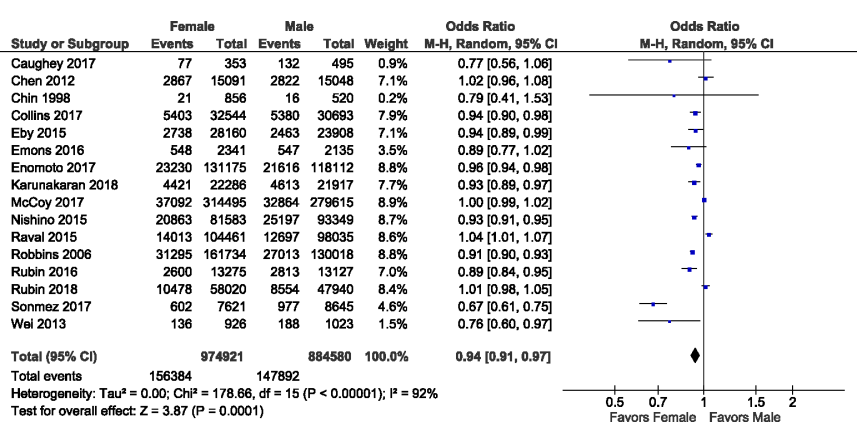

Figure 2 Forest plot of 16 studies reporting gender as a risk factor.

another study ${ }^{42}$ which was a subset of a previously selected study. ${ }^{43}$

\section{MA of 18 studies}

The funnel plot for gender was asymmetric but that for race was not. The Egger regression test, however, did not suggest any evidence of publication bias (all $p>0.1$ ) for any of the risk factors under consideration.

\section{Gender}

The analysis of the effect of gender on 30-day readmission included 16 studies $^{9} 1014-16303234-373943-4547$ involving 2163777 adult patients with DM (1032472 males and 1131305 females). One study ${ }^{45}$ reported males having significantly lower risk than females in being readmitted within 30 days, while six studies ${ }^{9} 1632343743$ did not show a significant gender effect. However, the overall pooled estimate (figure 2) found females to have a significantly lower risk of 30-day unplanned hospital readmission ( $\mathrm{OR}=0.94,95 \%$ CI 0.91 to 0.97 ).

\section{Age}

Due to the varying cut-offs in the studies, we were only able to include eight studies ${ }^{15} 163036-384344$ based on a cut-off at 65 years. There were 887353 patients aged $\geq 65$ years as compared with 608471 patients aged $<65$ years. Although two studies ${ }^{15} 37$ suggested increased age was negatively associated with 30 -day readmission, aged $\geq 65$ years showed a significant positive association with 30-day hospital readmission in the pooled analysis $(\mathrm{OR}=1.23$, 95\% CI 1.08 to 1.40 ) (table 2).

Table 2 Pooled OR estimates of specific risk factors (\%) and associated $95 \% \mathrm{Cl}$

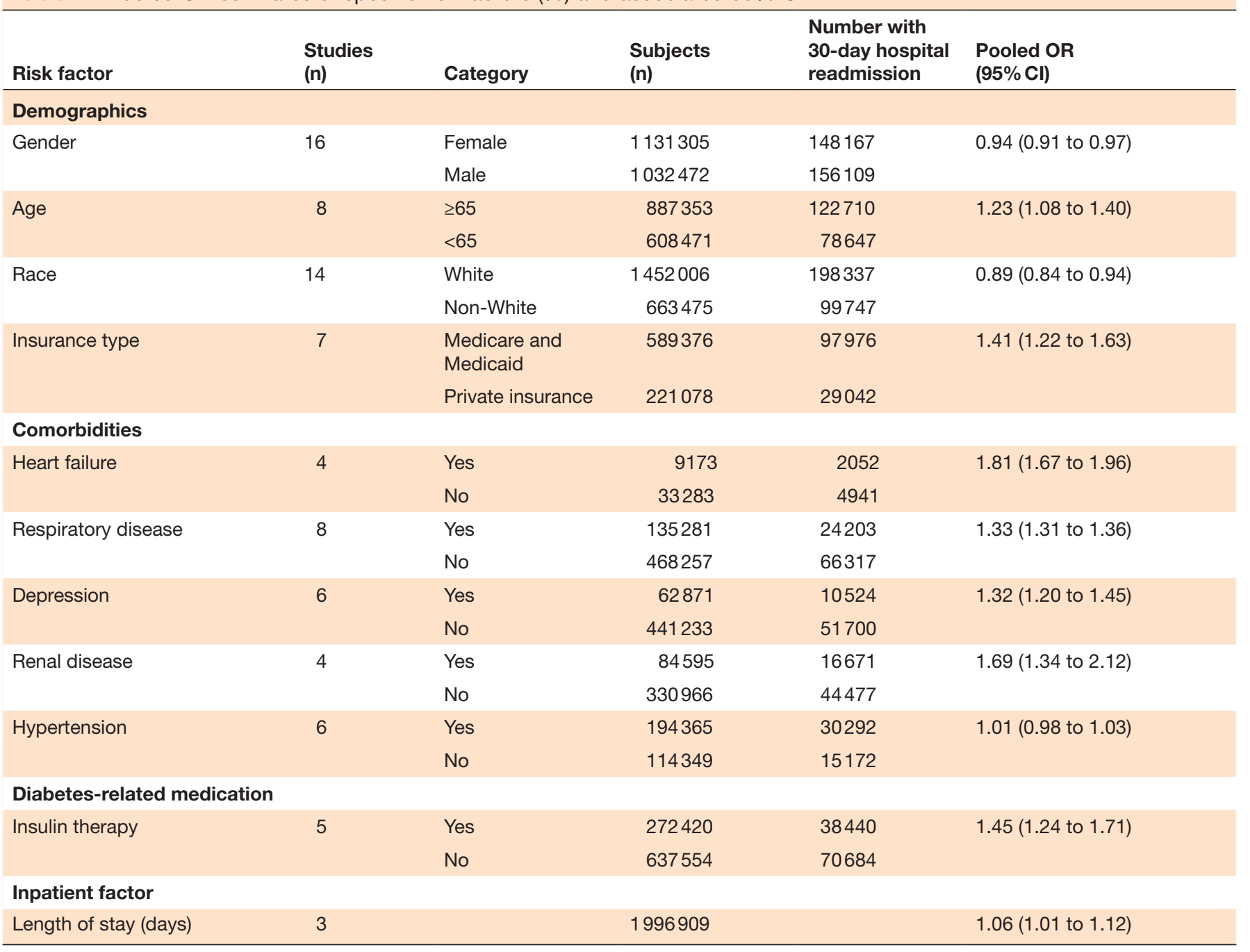




\section{Race}

Analysis of the pooled effect of race on 30-day hospital readmission included 14 studies $^{9} 1014153134-373943-4547$ involving 2115481 patients (1452006 White vs 663475 non-White). One small study ${ }^{34}(\mathrm{n}=1376)$ showed a very large relative risk reduction of 30-day readmission in White $(\mathrm{OR}=0.18,95 \%$ CI 0.09 to 0.35$)$. On the other hand, another study ${ }^{44}$ reported that being White is associated with increased risk of 30-day hospital readmission. The pooled estimate indicated a lower risk of 30-day unplanned hospital readmission in White as compared with non-White ( $\mathrm{OR}=0.89,95 \%$ CI 0.84 to 0.94$)$.

\section{Health insurance type}

Seven studies ${ }^{9} 101415363739$ based on 810454 subjects (589376 Medicare and/or Medicaid plan vs 221078 private insurance) were included in the analysis of insurance type. Only one study ${ }^{9}$ presented a non-significant result. The pooled analysis demonstrated that patients under Medicare and/or Medicaid plan had a higher risk $(\mathrm{OR}=1.41,95 \%$ CI 1.22 to 1.63$)$ of being readmitted to the hospital within 30 days compared with those who were privately insured.

\section{Comorbidities}

Heart failure

Four studies ${ }^{14} 163237$ involving 42456 patients (9173 with heart failure vs 33283 without heart failure) were available for the analysis. Heart failure was associated with a higher risk of being readmitted to hospital within 30 days ( $\mathrm{OR}=1.81,95 \%$ CI 1.67 to 1.96 ).

\section{Respiratory disease}

The analysis of respiratory disease was based on eight studies ${ }^{9} 10141632363739$ involving 603538 patients. Two studies ${ }^{3236}$ did not show a significant effect but the overall result demonstrated that respiratory disease was a significant predictor for 30-day unplanned hospital readmission ( $\mathrm{OR}=1.33$, 95\% CI 1.31 to 1.36$)$.

\section{Depression}

Six studies ${ }^{9} 1016323645$ including a total of 504104 adult patients with DM, involved 62871 patients with depressive symptoms and 441233 without depressive symptoms. Two studies ${ }^{32} 36$ did not show any association between depressive symptoms and DM. The overall pooled estimate indicated that depression was a significant risk factor of 30-day hospital readmission ( $\mathrm{OR}=1.32,95 \% \mathrm{CI}$ 1.20 to 1.45$)$.

\section{Renal disease}

For the analysis of renal disease, there were four studies $^{14163236}$ including 415564 patients. The overall effect suggested that renal disease was associated with an increased risk of being readmitted to hospital within 30 days $(\mathrm{OR}=1.69,95 \%$ CI 1.34 to 2.12$)$.

\section{Hypertension}

Six studies ${ }^{9} 1016363739$ involving a total of 308714 patients were included in the analysis of hypertension. The findings were inconclusive with two studies each suggesting a positive, ${ }^{1637}$ negative $^{9}{ }^{36}$ or non-significant ${ }^{1039}$ association between hypertension and readmission. Consequently, the overall pooled estimate showed that hypertension was not a significant risk factor of 30-day unplanned hospital readmission $(\mathrm{OR}=1.01,95 \%$ CI 0.98 to 1.03$)$.

\section{Length of stay}

Based on the result from the four available studies ${ }^{1531} 3536$ involving 1996909 patients, the pooled analysis showed that longer LOS during the index admission was associated with increased risk of 30-day hospital readmission $(\mathrm{OR}=1.06,95 \% \mathrm{CI} 1.01$ to 1.12$)$.

\section{Insulin therapy}

Five studies ${ }^{9} 10163943$ involving 909974 patients were analyzed for the effect of insulin therapy. The pooled estimate demonstrated that insulin therapy was associated with increased risk of being readmitted to hospital within 30 days $(\mathrm{OR}=1.45,95 \%$ CI 1.24 to 1.71$)$.

\section{DISCUSSION}

Identifying risk factors of 30-day unplanned hospital readmission among a heterogeneous diabetes population is important to healthcare professionals and policymakers when planning SME programs for more effective patient-centered health education. As there is no one-size-fits-all approach to managing diabetes, understanding these risk factors is crucial for providing individualized SME for each patient. This is the first SR with MA to demonstrate that gender, age, race, health insurance type, comorbidities including heart failure, respiratory disease, depression and renal disease, LOS as well as use of insulin therapy were significantly associated with 30-day unplanned hospital readmission.

Our findings are consistent with those reported in a recent SR by Robbins $e t a l,{ }^{50}$ which did not quantify the effects of the risk factors. In contrast, we had specifically quantified the effect of four different comorbidities (namely heart failure, respiratory disease, depression, and renal disease) and other patient characteristics which were significantly associated with increased risk of 30-day hospital readmission among adult patients with DM.

\section{Patient characteristics and social determinants}

The observed reduction in risk of readmission in females may be explained by several factors. One study demonstrated that hospitalized female patients with DM had fewer microvascular complications. ${ }^{51}$ Apart from reporting better support from diabetes healthcare providers, and being more likely than men to receive $\mathrm{SME},{ }^{52}$ it has also been suggested that women were better than men in chronic disease management. ${ }^{53}$ Despite the significant gender differences in health outcomes, healthcare management plans do not take this into account. ${ }^{54}$ Given that men with DM have a higher risk of unplanned 30-day hospital readmission than women, 
resources should be used to understand how such risk may be mitigated.

A possible reason for the positive association between age and the risk of 30-day hospital readmission was the associated medical morbidities among older patients. ${ }^{55}$ Elderly patients with chronic conditions may also have lower health literacy which potentially affects SME and increases the likelihood of unplanned hospital readmissions ${ }^{56}$ thus emphasizing a need for resource allocation to this vulnerable group. However, such findings should be interpreted with caution because hospital readmission policies may also affect readmission rates. For example, in one study examining older men with heart failure and pneumonia, readmission rates in non-Veterans Affairs hospitals were lower than Veterans Affairs hospitals ${ }^{57}$ because Centers for Medicare and Medicaid Services imposed financial penalties on the former for overconsumption of health services.

Belonging to the White race had a protective effect on 30-day hospital readmission suggesting health disparities between major and minor (non-White) ethnic groups. Generally, Black and Hispanic patients have been reported to receive less effective health services including diabetes monitoring than White patients. ${ }^{58}$ The minority races were also found to be disadvantaged in the US health system and were less likely to have insurance. ${ }^{59}$ Having a private insurance plan, an indicator of higher SES, ${ }^{60}$ was shown to have a protective effect on 30-day hospital readmission. Better self-management in DM has been shown to be significantly associated with higher $\mathrm{SES}^{61}$ and this may explain the lower readmission rates among the privately insured. This highlights the importance of universal health coverage to provide equal access to healthcare facilities. Racial disparities in healthcare access in the USA were significantly reduced after the Affordable Care Act health insurance was fully implemented in 2014. ${ }^{62}$ Healthcare practitioners should therefore be cognizant of the potential health disparities due to race, which may also be related to SES.

\section{Comorbidities}

Several studies have suggested the coexistence of heart failure and $\mathrm{DM}^{63}$ and the association between microvascular complications of DM and heart failure. ${ }^{64}$ Insulin resistance and the resulting hyperglycemia can lead to the development and progression of atherosclerotic lesions, the main causal factor of cardiovascular disease. ${ }^{65}$ The Atherosclerosis Risk in Communities Study ${ }^{66}$ has suggested myocardial damage in patients with DM, while the Framingham Heart Study has demonstrated a relationship between DM and poorer pulmonary function. ${ }^{67}$ The association between DM and poor prognosis in patients with respiratory diseases ${ }^{68}$ highlights the importance of maintaining good glycemic status to improve this adverse relationship. ${ }^{67}$ Although common causes of readmission among renal patients included abnormal glucose metabolism and hyperinsulinemia, ${ }^{69}$ adult patients with DM with renal disease might also be readmitted within
30 days for unplanned surgical procedure such as catheter vascular access. ${ }^{70}$ Thirty-day hospital readmission in patients with depression ${ }^{71}$ and uncontrolled hypertension may be attributed to poor self-care management such as medication non-adherence. ${ }^{72}$ In our study, however, we could not ascertain if the lack of association between hypertension and 30-day hospital readmission was related to medication non-adherence since such information was not reported in the selected studies.

Many adult patients with DM have other concurrent long-term medical conditions such as heart failure, respiratory diseases, depression, and renal disease. The results of this MA suggest that these patients have a higher risk of readmission and they should therefore be monitored carefully.

\section{Inpatient factor: LOS}

Several studies ${ }^{73}$ demonstrated that extended LOS in the index admission predicted hospital readmission; we found a similar relationship in patients with DM. The associated treatment of comorbidities and diabetes complications ${ }^{74}$ requires a complex management and longer LOS. Notably, LOS is a reflection of disease complexity and severity.

\section{Insulin therapy}

Current evidence suggests that nearly half of the patients who started insulin therapy had already developed diabetes-related complications. ${ }^{75}$ Thus, a 30-day unplanned hospital readmission could be related to underlying diabetic macrovascular and microvascular complications. On the other hand, compliance to insulin therapy is generally unsatisfactory ${ }^{76}$ with possible side effects such as hypoglycemia. ${ }^{77}$ The use of any insulin therapy is an important patient safety concern and our finding suggests that its use warrants a more vigilant monitoring, particularly among older patients. ${ }^{78}$

\section{Further discussions of other limitations}

Limitations of this study included the omission of known important risk factors such as the Diabetes Complications Severity Index and the Charlson Comorbidity Index. The information on these indices was not consistently captured in the different studies, thus posing difficulty for inclusion in the synthesis. In addition, more than twothirds of the selected papers included both T1DM and T2DM without a separate breakdown of each type. Thus, subgroup analysis on the risk factors according to type of diabetes could not be performed. Owing to the nature of the respective diseases, T1DM and T2DM may have different 30-day readmission risk factors and this may warrant further investigation in future studies.

\section{CONCLUSION}

Although most of the identified risk factors such as being female, being aged $\geq 65$ years, White, and having comorbidities like heart failure and renal disease are not modifiable, an understanding of their impact on disease 
outcomes is relevant to health professionals and policymakers for developing and updating clinical practice guidelines to reduce 30-day unplanned hospital readmission. Better management and monitoring of multiple comorbidities associated with diabetes is recommended to delay the progression of complications associated with $\mathrm{DM}$, thus reducing the risk of 30-day unplanned hospital readmission.

\section{Author affiliations}

${ }^{1}$ Saw Swee Hock School of Public Health, National University of Singapore, Singapore

${ }^{2}$ Health and Social Sciences, Singapore Institute of Technology, Singapore ${ }^{3}$ Respiratory and Critical Care Medicine, National University Hospital, Singapore ${ }^{4}$ National University Singapore, Yong Loo Lin School of Medicine, Singapore ${ }^{5}$ Department of Paediatrics, National University Hospital, Singapore

Contributors The first author (JGSS) drafted the manuscript and performed the statistical analysis. The last/corresponding author (BCT) is the key person who provides the research idea and advice, and guides the development at each stage including the writing of manuscript and statistical analysis. One coauthor (WPW) independently screened the titles and abstract together with the first author. SCQ and AM provided input on this manuscript and the research development.

Funding The authors have not declared a specific grant for this research from any funding agency in the public, commercial or not-for-profit sectors.

Competing interests None declared.

Patient consent for publication Not required.

Provenance and peer review Not commissioned; externally peer reviewed.

Data availability statement Data are available in a public, open access repository. All data relevant to the study are included in the article or uploaded as supplementary information.

Open access This is an open access article distributed in accordance with the Creative Commons Attribution Non Commercial (CC BY-NC 4.0) license, which permits others to distribute, remix, adapt, build upon this work non-commercially, and license their derivative works on different terms, provided the original work is properly cited, appropriate credit is given, any changes made indicated, and the use is non-commercial. See: http://creativecommons.org/licenses/by-nc/4.0/.

ORCID iD

Jade Gek Sang Soh http://orcid.org/0000-0003-2674-780X

\section{REFERENCES}

1 DeFronzo RA FE, Alberti K, Zimmet P, et al. International textbook of diabetes mellitus. 4 edn. GB: Wiley-Blackwell, 2015.

2 Poretsky L. Principles of diabetes mellitus. 3 edn. Cham: Springer International Publishing, 2017.

3 Nathan DM. Diabetes: advances in diagnosis and treatment. JAMA 2015;314:1052-62.

4 WHO. Global report on diabetes. World Health Organization, 2016.

5 Murray CJL, Vos T, Lozano R, et al. Disability-adjusted life years (DALYs) for 291 diseases and injuries in 21 regions, 1990-2010: a systematic analysis for the global burden of disease study 2010. Lancet 2012;380:2197-223.

6 Jiang HJ, Stryer D, Friedman B, et al. Multiple hospitalizations for patients with diabetes. Diabetes Care 2003;26:1421.

7 Wong ELY, Cheung AWL, Leung MCM, et al. Unplanned readmission rates, length of hospital stay, mortality, and medical costs of ten common medical conditions: a retrospective analysis of Hong Kong hospital data. BMC Health Serv Res 2011;11:149.

8 American Diabetes Association. Economic costs of diabetes in the U.S. in 2012. Diabetes Care 2013;36:1033-46.

9 Rubin DJ, Recco D, Turchin A, et al. External validation of the diabetes early re-admission risk indicator $\left(\right.$ derri $^{\text {TM }}\left({ }^{\prime}\right)$ ). Endocr Pract 2018;24:527-41.

10 Rubin DJ, Handorf EA, Golden SH, et al. Development and validation of a novel tool to predict Hospital readmission risk among patients with diabetes. Endocr Pract 2016;22:1204-15.

11 Rollins KE, Varadhan KK, Dhatariya K, et al. Systematic review of the impact of $\mathrm{HbA1c}$ on outcomes following surgery in patients with diabetes mellitus. Clin Nutr 2016;35:308-16.
12 Boreland L, Scott-Hudson M, Hetherington K, et al. The effectiveness of tight glycemic control on decreasing surgical site infections and readmission rates in adult patients with diabetes undergoing cardiac surgery: a systematic review. Heart Lung 2015;44:430-40.

13 Seuring T, Archangelidi O, Suhrcke M. The economic costs of type 2 diabetes: a global systematic review. Pharmacoeconomics 2015;33:811-31.

14 Enomoto LM, Shrestha DP, Rosenthal MB, et al. Risk factors associated with 30-day readmission and length of stay in patients with type 2 diabetes. J Diabetes Complications 2017;31:122-7.

15 Robbins JM, Webb DA, Robbins JM. Diagnosing diabetes and preventing rehospitalizations: the urban diabetes study. Med Care 2006;44:292-6.

16 Chen JY, Ma Q, Chen $\mathrm{H}$, et al. New bundled world: quality of care and readmission in diabetes patients. J Diabetes Sci Technol 2012;6:563-71.

17 Beck J, Greenwood DA, Blanton L, et al. 2017 national standards for diabetes self-management education and support. Diabetes Care 2017;40:1409-19.

18 Diabetes Canada Clinical Practice Guidelines Expert Committee, Sherifali D, Berard LD, et al. Self-Management education and support. Can J Diabetes 2018;42:S36-41.

19 Moher D, Shamseer L, Clarke M, et al. Preferred reporting items for systematic review and meta-analysis protocols (PRISMA-P) 2015 statement. Syst Rev 2015;4:1.

20 Morrison A, Polisena J, Husereau D, et al. The effect of englishlanguage restriction on systematic review-based meta-analyses: a systematic review of empirical studies. Int J Technol Assess Health Care 2012;28:138-44.

21 Williams DR, Priest N, Anderson NB. Understanding associations among race, socioeconomic status, and health: patterns and prospects. Health Psychol 2016;35:407.

22 Hartling L, Featherstone R, Nuspl M, et al. Grey literature in systematic reviews: a cross-sectional study of the contribution of non-English reports, unpublished studies and dissertations to the results of meta-analyses in child-relevant reviews. BMC Med Res Methodol 2017;17:64.

23 Mull HJ, Chen Q, O'Brien WJ, et al. Comparing 2 methods of assessing 30-day readmissions: what is the impact on hospital profiling in the Veterans health administration? Med Care 2013;51:589.

24 Veritas Health Innovation. Covidence systematic review software: Melbourne, Australia. Available: www.covidence.org

25 The Nordic Cochrane Centre, The Cochrane Collaboration. Review manager (RevMan). version 5.3. Copenhagen: The Nordic Cochrane Centre, The Cochrane Collaboration, 2014.

26 Lo CK-L, Mertz D, Loeb M. Newcastle-Ottawa scale: comparing reviewers' to authors' assessments. BMC Med Res Methodol 2014;14:45

27 Orimo $\mathrm{H}$, Ito $\mathrm{H}$, Suzuki T, et al. Reviewing the definition of "elderly". Geriatr Gerontol Int 2006;6:149-58.

28 Julian PTH, Sally G. Cochrane handbook for systematic reviews of interventions. Queensland: John Wiley \& Sons, 2008.

29 Egger M, Davey Smith G, Schneider M, et al. Bias in meta-analysis detected by a simple, graphical test. BMJ 1997;315:629-34.

30 Sonmez H, Kambo V, Avtanski D, et al. The readmission rates in patients with versus those without diabetes mellitus at an urban teaching hospital. J Diabetes Complications 2017;31:1681-5.

31 Bennett KJ, Probst JC, Vyavaharkar M, et al. Lower rehospitalization rates among rural Medicare beneficiaries with diabetes. $J$ Rural Health 2012;28:227-34.

32 Caughey GE, Pratt NL, Barratt JD, et al. Understanding 30-day re-admission after hospitalisation of older patients for diabetes: identifying those at greatest risk. Med J Aust 2017;206:170-5.

33 Chen H-F, Homan S, Carlson E, et al. The impact of race and neighborhood racial composition on preventable readmissions for diabetic Medicare home health beneficiaries. J Racial Ethn Health Disparities 2017;4:648-58.

34 Chin MH, Zhang JX, Merrell K. Diabetes in the African-American Medicare population. morbidity, quality of care, and resource utilization. Diabetes Care 1998;21:1090.

35 Collins J, Abbass IM, Harvey R, et al. Predictors of all-cause 30 day readmission among Medicare patients with type 2 diabetes. Curr Med Res Opin 2017;33:1517-23.

36 Eby E, Hardwick C, Yu M, et al. Predictors of 30 day hospital readmission in patients with type 2 diabetes: a retrospective, casecontrol, database study. Curr Med Res Opin 2015;31:107-14.

37 Emons MF, Bae JP, Hoogwerf BJ, et al. Risk factors for 30day readmission following hypoglycemia-related emergency room and inpatient admissions. BMJ Open Diabetes Res Care 2016;4:e00160. 
38 Jiang HJ, Andrews R, Stryer D, et al. Racial/ethnic disparities in potentially preventable readmissions: the case of diabetes. Am J Public Health 2005;95:1561-7.

39 Karunakaran A, Zhao H, Rubin DJ. Predischarge and postdischarge risk factors for hospital readmission among patients with diabetes. Med Care 2018;56:634-42.

40 Lin P-J, Kent DM, Winn A, et al. Multiple chronic conditions in type 2 diabetes mellitus: prevalence and consequences. Am J Manag Care 2015;21:e23-34.

41 Lipska KJ, Ross JS, Wang Y, et al. National trends in US hospital admissions for hyperglycemia and hypoglycemia among Medicare beneficiaries, 1999 to 2011. JAMA Intern Med

2014;174:1116-24.

42 McCoy RG, Herrin J, Lipska KJ, et al. Recurrent hospitalizations for severe hypoglycemia and hyperglycemia among U.S. adults with diabetes. J Diabetes Complications 2018;32:693-701.

43 McCoy RG, Lipska KJ, Herrin J, et al. Hospital readmissions among commercially insured and Medicare advantage beneficiaries with diabetes and the impact of severe hypoglycemic and hyperglycemic events. J Gen Intern Med 2017;32:1097-105.

44 Nishino Y, Gilmour S, Shibuya K. Inequality in diabetes-related hospital admissions in England by socioeconomic deprivation and ethnicity: facility-based cross-sectional analysis. PLoS One 2015;10:e0116689.

45 Raval AD, Zhou S, Wei W, et al. 30-Day readmission among elderly medicare beneficiaries with type 2 diabetes. Popul Health Manag 2015;18:256-64

46 Takahashi PY, St Sauver JL, Finney Rutten LJ, et al. Health outcomes in diabetics measured with Minnesota community measurement quality metrics. Diabetes Metab Syndr Obes 2015;8:1-8.

47 Wei NJ, Wexler DJ, Nathan DM, et al. Intensification of diabetes medication and risk for 30-day readmission. Diabet Med 2013;30:e56-62.

48 Islam MM, lqbal U, Walther B, et al. Benzodiazepine use and risk of dementia in the elderly population: a systematic review and metaanalysis. Neuroepidemiology 2016;47:181-91

49 Deas I, Robson B, Wong C, et al. Measuring neighbourhood deprivation: a critique of the index of multiple deprivation. Environment and Planning C: Government and Policy 2003;21:883-903.

50 Robbins TD, Lim Choi Keung SN, Sankar S, et al. Risk factors for readmission of inpatients with diabetes: a systematic review. $J$ Diabetes Complications 2019;33:398-405.

51 Patel N, Pinkhasova D, Donihi AMY, et al. 1556-P: gender differences in glycemic control, microvascular and macrovascular complications in hospitalized patients with diabetes. Diabetes 2019;68:1556-P.

52 Gucciardi E, Wang SC-T, DeMelo M, et al. Characteristics of men and women with diabetes: observations during patients' initial visit to a diabetes education centre. Can Fam Physician 2008;54:219-27.

53 Flynn FJ, Ames DR. What's good for the goose may not be as good for the gander: the benefits of self-monitoring for men and women in task groups and dyadic conflicts. J Appl Psychol 2006;91:272-81.

54 Regitz-Zagrosek V. Sex and gender differences in health. EMBO Rep 2012:13:596-603.

55 García-Pérez L, Linertová R, Lorenzo-Riera A, et al. Risk factors for hospital readmissions in elderly patients: a systematic review. QJM 2011;104:639-51.

56 Clouston SAP, Manganello JA, Richards M. A life course approach to health literacy: the role of gender, educational attainment and lifetime cognitive capability. Age Ageing 2017;46:493-9.

57 Nuti SV, Qin L, Rumsfeld JS, et al. Association of admission to Veterans affairs hospitals vs non-veterans affairs hospitals with mortality and readmission rates among older men hospitalized with acute myocardial infarction, heart failure, or pneumonia. JAMA 2016;315:582-92.

58 Schpero WL, Morden NE, Sequist TD, et al. For selected services, blacks and hispanics more likely to receive low-value care than whites. Health Aff 2017;36:1065-9.

59 Lillie-Blanton M, Hoffman C. The role of health insurance coverage in reducing racial/ethnic disparities in health care. Health Aff 2005;24:398-408.

60 Shavers VL. Measurement of socioeconomic status in health disparities research. J Natl Med Assoc 2007;99:1013-23.

61 Walker RJ, Smalls BL, Egede LE. Social determinants of health in adults with type 2 diabetes--contribution of mutable and immutable factors. Diabetes Res Clin Pract 2015;110:193-201.

62 Chen J, Vargas-Bustamante A, Mortensen K, et al. Racial and ethnic disparities in health care access and utilization under the Affordable care act. Med Care 2016;54:140-6.

63 Seferović PM, Petrie MC, Filippatos GS, et al. Type 2 diabetes mellitus and heart failure: a position statement from the heart failure association of the European Society of cardiology. Eur J Heart Fail 2018;20:853-72.

64 Cheung N, Bluemke DA, Klein R, et al. Retinal arteriolar narrowing and left ventricular remodeling: the multi-ethnic study of atherosclerosis. J Am Coll Cardiol 2007;50:48-55.

65 Niccoli T, Partridge L. Ageing as a risk factor for disease. Curr Biol 2012;22:R741-52

66 Selvin E, Lazo M, Chen Y, et al. Diabetes mellitus, prediabetes, and incidence of subclinical myocardial damage. Circulation 2014;130:1374-82

67 Walter RE, Beiser A, Givelber RJ, et al. Association between glycemic state and lung function. Am J Respir Crit Care Med 2003; $167: 911-6$

68 Ho T-W, Huang C-T, Ruan S-Y, et al. Diabetes mellitus in patients with chronic obstructive pulmonary disease-the impact on mortality. PLoS One 2017;12:e0175794.

69 Sechi LA, Catena C, Zingaro L, et al. Abnormalities of glucose metabolism in patients with early renal failure. Diabetes 2002;51:1226-32.

70 Flythe JE, Katsanos SL, Hu Y, et al. Predictors of 30-day hospital readmission among maintenance hemodialysis patients: a hospital's perspective. Clin J Am Soc Nephrol 2016;11:1005-14.

71 Lin EHB, Katon W, Von Korff M, et al. Relationship of depression and diabetes self-care, medication adherence, and preventive care. Diabetes Care 2004;27:2154.

72 Rosen OZ, Fridman R, Rosen BT, et al. Medication adherence as a predictor of 30-day hospital readmissions. Patient Prefer Adherence 2017;11:801-10.

73 Hasan O, Meltzer DO, Shaykevich SA, et al. Hospital readmission in general medicine patients: a prediction model. $J$ Gen Intern Med 2010;25:211-9.

74 Liu X, Guo Y, Li D, et al. The prevalence and long-term variation of hospital readmission for patients with diabetes in Tianjin, China: a cross-sectional study. Medicine 2017;96:e7953.

75 Boels AM, Vos RC, Hermans TGT, et al. What determines treatment satisfaction of patients with type 2 diabetes on insulin therapy? an observational study in eight European countries. BMJ Open 2017;7:e016180.

76 Davies MJ, Gagliardino JJ, Gray LJ, et al. Real-world factors affecting adherence to insulin therapy in patients with type 1 or type 2 diabetes mellitus: a systematic review. Diabet Med 2013;30:512-24.

77 McCall AL. Insulin therapy and hypoglycemia. Endocrinol Metab Clin North Am 2012;41:57-87.

78 Lysy Z, Fung K, Giannakeas V, et al. The association between insulin initiation and adverse outcomes after hospital discharge in older adults: a population-based cohort study. J Gen Intern Med 2019;34:575-82. 